\title{
Olecranon Lesions Caused by Onchocerca skrjabini in Wild Japanese Serows (Capricornis crispus)
}

\author{
Yoshitaka SUZUKI, Shigehiko UNI'), Takeshi KOMATSU, Yoshio YAMAMOTO, and Yasuro ATOJI
}

Laboratory of Veterinary Anatomy, Faculty of Agriculture, Gifu University, Gifu 501-11 and ${ }^{1}$ Department of Medical Zoology, Osaka City University Medical School, Osaka 545, Japan

(Received 26 November 1996/Accepted 16 January 1997)

ABSTRACT. Wild Japanese serows (Capricornis crispus) were found to have parasitic lesions in tendons that attached the musculus tricepus brachii to the olecranon. Histopathological study of the lesions showed chronic tendinitis with multiple granulation nodules around the worms. The lesions were found in 138 of the 353 serows examined and were more frequent in aged animals than young ones. Transverse ridges on the cuticle of the female midbody, the sizes and morphological features of the spicules, and the arrangement of the caudal papillae of the males showed the parasite to be Onchocerca skrjabini. Therefore, O. skrjabini causes olecranon lesions in addition to fibrous bursa formation in carpal and tarsal regions of the Japanese serows. - KEY wORDS: Japanese serow, olecranon, onchocerciasis.

Wild Japanese serows (Capricornis crispus) captured in Gifu Prefecture, Japan, have been found to have onchocerciasis with two kinds of pathological lesions visible in the subcutaneous tissue [5]. In one kind, yellowish-gray nodules are found sporadically in various parts of the body, and in the other, fibrous bursa formation is found mostly in the carpal and tarsal regions.

Different Onchocerca species were found in the lesions, and numbered 1 and 2, respectively. Later, species 1 was named O. suzukii Yagi, Bain and Shoho, 1994, and species 2 was found to be O. skrjabini Rukhlyadev, 1964 [8]. O. tarsicola (a synonym of $O$. skrjabini) has been found free in the feet of red deer, Cervus elephus, in Germany [2], but lesions were not found, nor had lesions caused by $O$. skrjabini been detected before in other host animals, to the best of our knowledge.

The purpose of this report is to describe the occurrence and pathological findings of olecranon lesions caused by $O$. skrjabini. Characteristic features of $O$. skrjabini before and after being sectioned also are reported.

Materials in the present study were from 353 individuals (57 fawns, 46 yearlings, and 250 adults) captured between December 1983 and March 1984 in Gifu Prefecture in accordance with the policy of the Agency of Cultural Affairs, Japan, for conservation and control of Japanese serows. Worms were extracted from olecranon lesions preserved in formalin solution and sectioned for histological inspection.

Upon necropsy, parasitologic lesions were found in tendons attaching the musculus tricepus brachii to the olecranon (Fig. 1). Cut surfaces of affected tendons showed hard, yellowish-white lesions measuring at the widest 0.7$1.8 \mathrm{~cm}$, without clear margins. In severe cases, many brownish patches were found scattered throughout the lesions. Histopathological study of the lesions showed chronic parasitic tendinitis with multiple granulation nodules around the worms (Fig. 2). Affected tendon tissues showed other changes as well, such as pyknosis of tendon cells, edematous dissociation of collagenous fiber bundles, hyalinization, and metaplastic alteration of chondroid tissue.
Near the adult worms, masses of microfilariae were often found.

In some cases, individual microfilariae penetrated collagenous fiber bundles. In severe infections, interstitial cell infiltration by eosinophils, lymphocytes, macrophages, and plasma cells was occasionally observed in neighboring muscle tissue. Olecranon lesions were found in 138 of the 353 serows examined and were found in a greater proportion of older animals.

Parasitologic examinations were done of the anterior portions of one female and three males and the posterior portions of one female and two males. Midbody portions of male and female worms also were examined.

The body width of the females was 153-398 $\mu \mathrm{m}$. The muscular portion of the esophagus was $612 \mu \mathrm{m}$ long, and the distances of the nerve ring and vulva from the anterior end were 224 and $408 \mu \mathrm{m}$. At the midbody, the intervals between transverse ridges were 153-189 $\mu \mathrm{m}$, and the intervals between internal striae were $36-49 \mu \mathrm{m}$. The ridges were not branched over lateral chords (Fig. 3). Transverse sections of the female midbody showed three to five muscle cells (Fig. 4). Microfilariae (extracted from the uteri at the midbody region) were 192-270 $\mu \mathrm{m}$ long and 3-5 $\mu \mathrm{m}$ wide.

The body width of the male was $138 \mu \mathrm{m}$. The nerve ring was $208-214 \mu \mathrm{m}$ from the anterior end. The esophagus measured $1989 \mu \mathrm{m}$ long (muscular portion, 1,020 $\mu \mathrm{m}$ and glandular portion, $969 \mu \mathrm{m})$. The tail was 78 or $145 \mu \mathrm{m}$ long. The length of the left spicule was 260 or $299 \mu \mathrm{m}$; that of the right spicule was 91 or $104 \mu \mathrm{m}$, with cuticle that was broad, tubular, and heavily sclerotized proximally, narrowing distally to a knobbed end (Fig. 5). The caudal papillae were arranged with one precloacal papilla and two groups of caudal pairs. The group near the cloaca was composed of five papillae on the right and four or five papillae on the left and one pair subventrally; the other group, at the end of the tail, was composed of four pairs (the eighth on the right and the seventh on the left in Fig. 5 seemed to accompany with phasmidial pores). Caudal alae were present.

The transverse ridges on the external cuticular layer of 

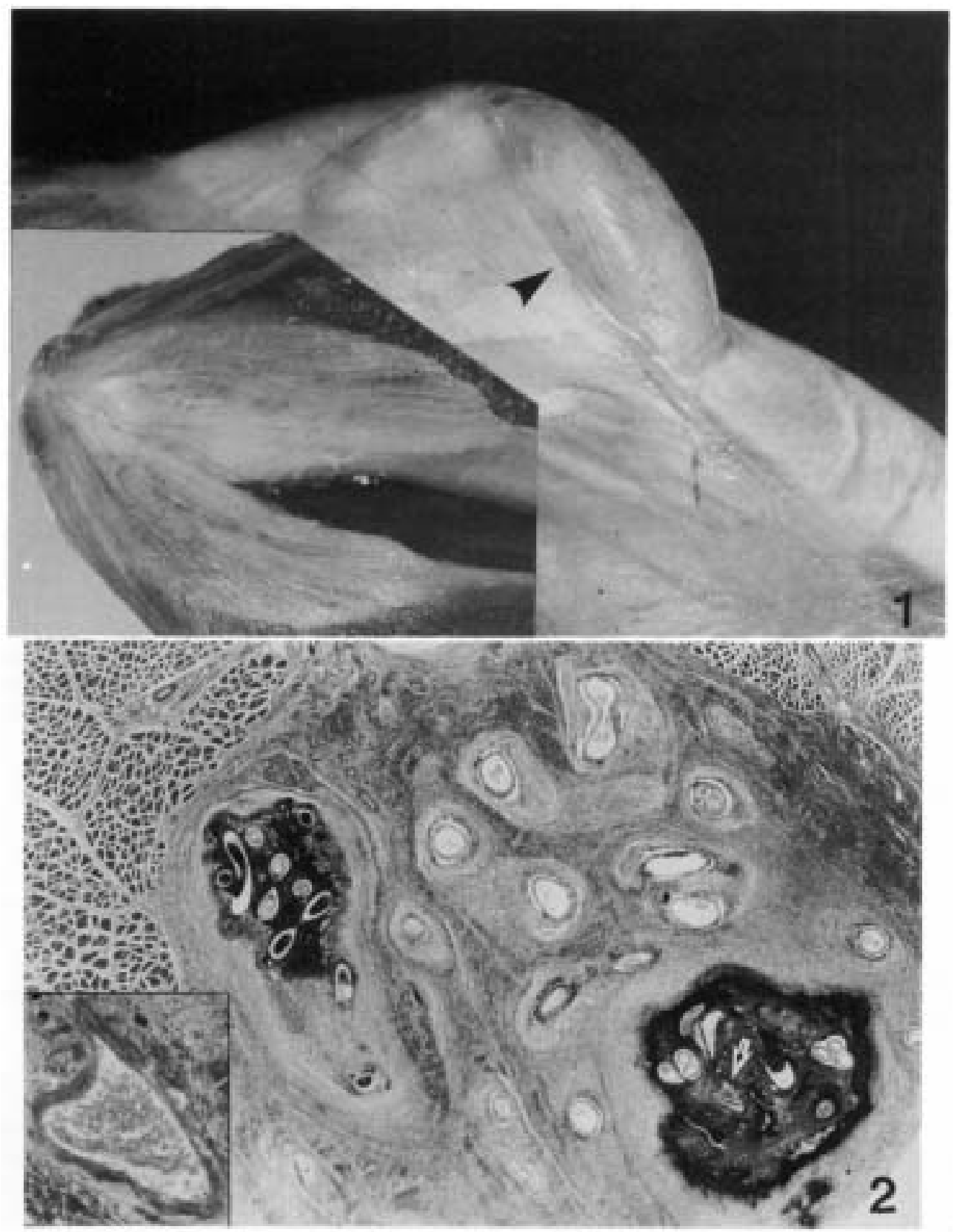

Fig. 1. Focal swelling of a tendon (arrowhead). Inset: Cut surface of the lesion.

Fig. 2. Multiple parasitic granulation nodules in a tendon. HE stain. $\times 18$. Inset: Higher magnification of area near arrow. Many microfilariae can be seen. $\times 90$.

the female midbody regions, the sizes and morphologic features of the spicules, and the arrangement of the caudal papillae of the male specimens showed the parasites to be O. skrjabini described by Bain and Schulz-Key [2] and Yagi et al. [8]. However, the vulva was more anterior than described before [8]. The microfilariae were small, suggesting their immaturity.

Thus, our findings indicate that $O$. skrjabini is the causative agent of oleclanon lesions and fibrous bursa formation in carpal and tarsal regions in wild serows. $O$. suzukii, in contrast, causes only subcutaneous nodules in various parts of the torso of serows [5, 8].

Recently, two cases of zoonotic onchocerciasis caused by $O$. gutturosa in humans were reported in Oita, Japan [3, 7]. Six Onchocerca species have been found in Japan: $O$. lienalis, O. gutturosa, and an Onchocerca sp. in cattle, $O$. 

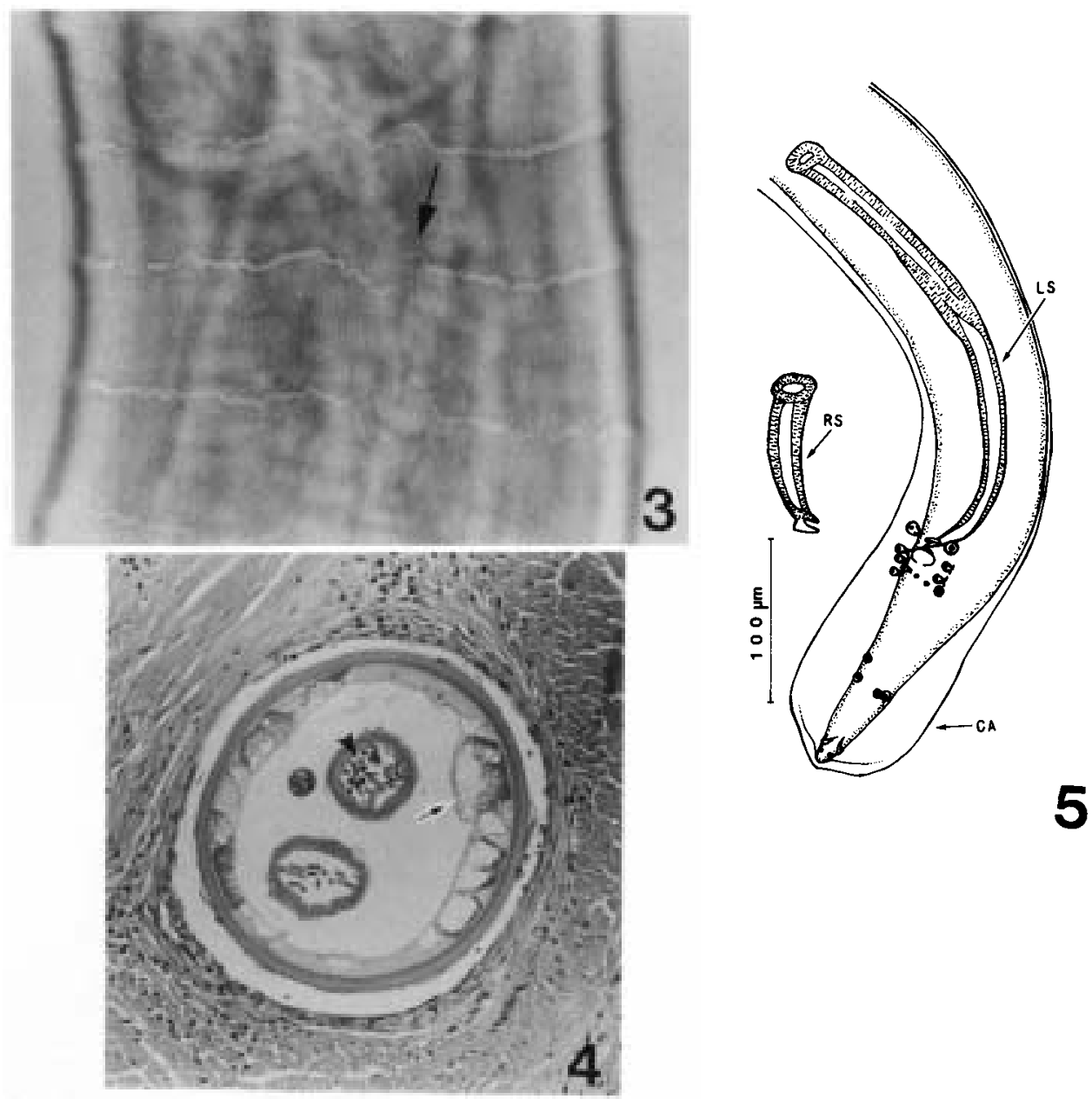

Fig. 3. Transverse ridges on the external cuticular layer of the midbody of a female Onchocerca skrjabini. The ridges are not branched over the lateral chord (arrow) $\times 150$.

Fig. 4. Cross-section of the midbody of a female. A few muscle cells are seen (arrow). Microfilariae are seen in the uteri (arrowhead). $\times 130$.

Fig. 5. Camera lucida drawings of the caudal region of a male. CA, caudal ala; LS, left spicule; RS, right spicule.

cervicalis in horses, and both $O$. suzukii and O. skrjabini in serows. Human infection caused by $O$. skrjabini has not been reported. O. tarsicola is transmitted by blackflies (Simulium ornatum) in European cervids. O. gutturosa also is transmitted by this blackfly as well as by biting midges (Culicoides) in cattle in Europe [1]. Simulium bidentatum transmits $O$. gutturosa in Oita, Japan, being not only boviphilic but also anthropophilic [6]. Vector species of $O$. skrjabini parasitizing Japanese serows have not been identified, but the possibility of human infection caused by O. skrjabini remains open.

Cross-sections of $O$. skrjabini closely resembled those of O. gutturosa; both species have conspicuous transverse ridges [7]. The ridges of $O$. gutturosa are branched over lateral chords [4]. The ridges of $O$. skrjabini in the midbody are not branched. In geographic locations where both species have been found, these features of the ridges may be helpful in identification of the species in zoonotic cases in humans. Surveys of the geographic distribution of onchocerciasis in serows also may give information useful in distinguishing species.

ACKNOWLEDGEMENT. We thank Ms. C. Latta for reading the manuscript.

\section{REFERENCES}

1. Anderson, R. C. 1992. pp. 485-487. Nematode Parasites of Vertebrates: Their Development and Transmission, C.A.B International, Wallingford, Oxfordshire, UK.

2. Bain, O. and Schulz-Key, H. 1974. Tropenmed. Parasitol. 25: 437-449.

3. Beaver, P. C., Yoshimura, H., Takayasu, S., Hashimoto, H., and Little, M. D. 1989. Am. J. Trop. Med. Hyg. 40: 298-300.

4. Eberhard, M. L. 1979. J. Parasitol. 65: 379-388. 
5. Suzuki, Y., Sugimura, M., Yagi, K., Ohbayashi, M., and Shoho, C. 1982. Jpn. J. Vet. Sci. 44: 823-825.

6. Takaoka, H. 1994. J. Med. Entomol. 31: 404-416.

7. Takaoka, H., Bain, O., Tajimi, S., Kashima, K., Nakayama,
I., Korenaga, M., Aoki, C., and Ostuka, Y. 1996. Parasite 3: 179-182.

8. Yagi, K., Bain, O., and Shoho, C. 1994. Parasite 1: 349-356. 